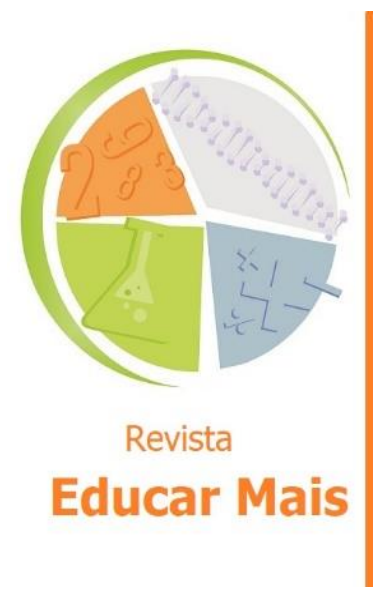

\title{
Corporeidade nas aulas de Educação Física de uma escola no Vale do Jequitinhonha em Minas Gerais
}

\author{
Corporeity in Physical Education classes at a school in Vale do \\ Jequitinhonha in Minas Gerais
}

Corporeidad en clases de Educación Física en una escuela del Valle Jequitinhonha en Minas Gerais

Heide Pereira Costa ${ }^{1}$; Carla Chagas Ramalho ${ }^{1}$

\section{RESUMO}

A Educação Física é um componente curricular obrigatório durante a Educação Básica, neste período a percepção da corporeidade deveria ser um fator importante para a compreensão do corpo de forma ampla. Desta forma, este trabalho tem como objetivo central analisar como alunos(as) e professoras do Ensino Médio, de uma escola estadual do Vale do Jequetinhonha (Minas Gerais) identificam a vivência da corporeidade durante as aulas de Educação Física e como conceituam corporeidade. Este estudo caracteriza-se por ser uma pesquisa descritiva de abordagem qualitativa. Utilizando dois questionários, um para cada grupo investigado, um grupo de 13 (treze) alunos(as) do $3^{\circ}$ ano do Ensino Médio, e outro com 2 (duas) professoras de Educação Física que atuam na escola pesquisada. A partir da análise do conteúdo, concluímos que a corporeidade ainda tem o seu conceito e a sua compreensão não totalmente definidos pelos(as) alunos(as) pesquisados(as), apesar das professoras salientarem a importância de trabalhar visando a corporeidade.

Palavras-chave: Educação Física; Corporeidade; Corpo.

\begin{abstract}
Physical Education is a mandatory curricular component during Basic Education, in this period the perception of corporeality should be an important factor for understanding the body in a broad way. Thus, this work aims to analyze how high school students and teachers from a state school in Vale do Jequetinhonha (Minas Gerais) identify the experience of corporeality during Physical Education classes and how they conceptualize corporeality. This study is characterized by being a descriptive research with a qualitative approach. using two questionnaires, one for each investigated group, a group of 13 (thirteen) students from the 3rd year of high school, and the other with 2 (two) Physical Education teachers who work at the researched school. From the content analysis, we conclude that corporeality still has its concept and its understanding not fully defined by the researched students, despite the teachers stressing the importance of working aiming at corporeality.
\end{abstract}

Keywords: PhysicalEducation; Corporeity; Body.

\section{RESUMEN}

La Educación Física es un componente curricular obligatorio durante la Educación Básica, en este período la percepción de corporalidad debe ser un factor importante para comprender el cuerpo de manera amplia. Así,

\footnotetext{
${ }^{1}$ Unimontes - Universidade Estadual de Montes Claros, Montes Claros/MG - Brasil.
} 
este trabajo tiene como principal objetivo analizar cómo estudiantes y profesores de secundaria, de una escuela pública en Vale do Jequetinhonha (Minas Gerais) identifican la experiencia de la corporalidad durante las clases de Educación Física y cómo conceptualizan la corporalidad. Este estudio se caracteriza por ser una investigación descriptiva con enfoque cualitativo. mediante dos cuestionarios, uno para cada grupo investigado, un grupo de 13 (trece) alumnos de 30 de Bachillerato, y el otro con 2 (dos) profesores de Educación Física que laboran en el colegio investigado. Del análisis de contenido se concluye que la corporeidad aún tiene su concepto y comprensión no completamente definidos por los estudiantes encuestados, a pesar de que los docentes enfatizan la importancia de trabajar por la corporeidad.

Palabras clave: Educación Física; Corporal; Cuerpo.

\section{INTRODUÇÃO}

O corpo humano é constituído por mais que músculos, articulações, ossos ou outros constituintes anatômicos. O corpo humano possui história, reflete crenças, norteia comportamentos, sendo um corpo vivo que vive em consonância com a realidade social e cultural que o norteia. Esta ação do corpo vivo é nomeada de corporeidade, pois tudo aquilo que é vivido e reconhecido é armazenado como forma de conhecimento em seu corpo, de forma resumida, podemos considerar a corporeidade como herança de todo o nosso processo (JOÃO; BRITO, 2004).

A corporeidade se relaciona diretamente com a Educação Física escolar, no contexto de educação escolarizada, ou deveria se relacionar, pois a Educação Física possui as práticas corporais como ferramenta para aprendizagem, através da cultura corporal do movimento, como podemos ver a seguir:

Nas aulas [de Educação Física], as práticas corporais devem ser abordadas como fenômeno cultural dinâmico, diversificado, pluridimensional, singular e contraditório. Desse modo, é possível assegurar aos alunos a (re)construção de um conjunto de conhecimentos que permitam ampliar sua consciência a respeito de seus movimentos e dos recursos para o cuidado de si e dos outros e desenvolver autonomia para apropriação e utilização da cultura corporal de movimento em diversas finalidades humanas, favorecendo sua participação de forma confiante e autoral na sociedade. (BRASIL, 2018, p. 213)

Dessa forma, a Educação Física deve ir além de proporcionar somente percepções relacionadas ao lado físico e/ou estético dos corpos, ela contribui de modo geral para a melhor assimilação do(a) aluno(a) com as suas possibilidades corporais (SOARES, 2002). Também se faz importante ressaltar, que a corporeidade não está presa aos limites do corpo, fisiologicamente falando, ela o transcende, prolongando o corpo através das diversas vivências pelas quais ele está sujeito atribuindo a ele uma bagagem de aprendizados (FREITAS, 1995).

Assim, este estudo fundamenta-se na importância de mostrar a corporeidade como parte integrante do conteúdo curricular da Educação Física, com foco no Ensino Médio, trazendo possíveis reflexões a respeito da visão dos corpos pelos(as) próprios(as)estudantes e professoras pesquisadas. Ao reforçar a pluralidade de conteúdos durante o Ensino Médio, tendo como enfoque a descoberta e conhecimento dos(as) alunos(as) dos seus próprios corpos, auxiliando-os a enxergar que seu corpo não é uma máquina a ser aprimorada, mas um corpo repleto de gestos e movimentos carregados de significados, histórias e sensibilidade (MOREIRA et al, 2010). 
Assim, este trabalho tem como objetivo principal analisar como os(as) alunos(as) e as professoras do Ensino Médio, em uma escola mineira do Vale do Jequitinhonha, identificam a vivência da corporeidade durante a aula de Educação Física. Este estudo caracteriza-se por ser uma pesquisa descritiva de abordagem qualitativa. O mesmo atende a todos os cuidados éticos previstos na Resolução 466/2012, sendo assim, foi solicitada aos(as) participantes da pesquisa a assinatura do termo de consentimento livre e esclarecido que foi submetido e aprovado pelo comitê de ética da instituição fomentadora da pesquisa².

A opção pela escola e pelo município em questão ocorreu por ser residência de uma das pesquisadoras, sendo assim escolhido por conveniência (GIL, 2008). Trata-se de uma instituição escolar pública onde é ofertado o ensino regular (Ensino Fundamental e Médio) pela rede estadual de ensino. Esta escola fica no município de Turmalina, na região de Minas Gerais conhecida como Vale do Jequitinhonha, esta cidade possui aproximadamente 18.000 (dezoito mil) habitantes ${ }^{3}$.

A pesquisa foi formada por um total de 15 indivíduos maiores de 18 anos, convidados(as) de maneira aleatória a participarem, dentre esses(as): 2 (duas) professoras de Educação Física e 13 (treze) alunos(as) atuantes e ingressos no $3^{\circ}$ ano do Ensino Médio, desta escola Estadual no Vale do Jequitinhonha em Minas Gerais. A coleta aconteceu no turno matutino durante uma das aulas teóricas de Educação Física. Em sua realização a pesquisa contou com dois questionários: para os professores com8 (oito) perguntas abertas e 2 (duas) fechadas: e para os(as) alunos(as) com 3 (três) perguntas abertas e 2 (duas) fechadas, que auxiliassem na consolidação dos objetivos da pesquisa.

Para manter o anonimato e garantir o sigilo da identidade de todos(as) pesquisados(as) daremos nomes fictícios a todas(os). Para as professoras pesquisadas iremos chamá-las de "Professora X" e "Professora Z"; a Professora X possui 31 anos e oito anos de formada; a professora Z possui 44 anos e é formada a 16 anos. 0 grupo definido como o de alunos(as) pesquisados(as) possui 13 (treze) estudantes, que serão nomeados por números romanos do I ao XIII, todos(as) maiores de idade e devidamente matriculados(as) no Ensino Médio da escola pesquisada, que denominaremos de Escola Vital.

Após passarmos os questionários para os dois grupos (alunos/alunas e professoras), criamos algumas categorias para tratamento das respostas, buscando consolidar os grupos de análise (BARDIN, 2016). As categorias ficaram definidas em: a corporeidade para os professores; a corporeidade para os alunos e as alunas.

Dividimos nosso artigo em duas partes de revisão de literatura, são elas: Corporeidade; Corporeidade na Educação Física escolar. Após esses tópicos, veremos os resultados e discussão da pesquisa.

\section{CORPOREIDADE}

O corpo, dentro da sua complexidade e magnitude conceitual, deve ser tratado como um paradigma tanto na educação quanto na ciência, pois o homem se conscientiza que não possui um corpo, mas que ele é um corpo. Assim o conceito de corporeidade está inteiramente ligado à filosofia e a compreensão sobre o corpo (MOREIRA, 1998). Santin (2013) faz uso de uma analogia para a

\footnotetext{
${ }^{2}$ Comitê de Ética da Universidade Estadual de Montes Claros (UNIMONTES) tendo o parecer no 3.289.271

${ }^{3}$ Informações coletadas pelo site da prefeitura < http://turmalina.mg.gov.br/prefeitura/historia-da-cidade/>, acesso em 10 de ago de 2020.
} 
compreensão de corporeidade por não se tratar de algo fácil, pois ela não é definida a partir de elementos objetivos como, por exemplo, o termo água. Mostrando assim, a importante diferença entre o conceito concreto e um conceito abstrato que estão ligados a algo palpável e a compreensão de significados mais profundos do que apenas a uma definição contida num dicionário, respectivamente (SANTIN, 2013).

Desta forma, o entendimento de corporeidade só é possível com a junção das definições, dos conceitos e das sabedorias tanto no âmbito da técnica e da ciência, da arte e da poesia, resultando de acordo com Moreira (1998) em um modelo multidimensional do ser humano.

A vida é multidimensional, pois como indivíduos ou como interagentes da sociedade e da cultura, somos seres que não se reduzem à política, embora nada escape a essa dimensão, à economia, à tecnologia. Mas verdade também é que nada escapa das dimensões subjetivas, afetivas e lúdicas. Essa multidimensionalidade não se encontra em nós de forma harmoniosa, mas coexiste no conflito, na contradição. A corporeidade é, assim, multifacetada, contraditória, energia que leva ao movimento impulsionado pelo conflito (MOREIRA, 1998, p.147).

A corporeidade baseada nas práticas positivistas, ou seja, que trata o corpo como algo mecânico e que deve ser trocado caso sofra danos, é caracterizada como disciplinadora, estabelecendo o controle externo do uso do corpo (SANTIN, 2013). Com esta visão, o corpo é transformado num alvo de interesse pensado ao seu uso, à sua eficiência e utilidade, tendo uma perspectiva de objeto manipulado e que passa por imposições como proibição, obrigação e limitação. Assim Moreira (2000, p.56) diz que "corpo pensado, perfeito, esquadrinhado, determinado, explicado, com reações previsíveis, disciplinado, jamais compreenderá a insustentável leveza do ser". Ainda nesta visão positivista, o corpo serve como um mecanismo simples, que deve ser treinado, preparado ou recuperado, tendo uma visão de utilidade deste corpo (INFORSATO; FIORANTE, 2010), e, dentro da nossa sociedade atual, o corpo útil é aquele que serve da melhor forma possível a propósitos racionais. Santin (2013) ressalta que a:

[...] imagem da corporeidade de nossa cultura racionalizada, cientifizada e industrializada em nada garante o cultivo do corpo, ao contrário, o reduz a um objeto de uso, um utensílio, uma ferramenta, a ser usada segundo a vontade de cada um ou, o que é pior, conforme os interesses econômicos, políticos e ideológicos de outros grupos (SANTIN, 2013, p.55).

A complexidade atribuída ao humano e ao corpo humano vai se desenhando, apontando para as múltiplas possibilidades através do corpo e com o corpo. Para Csordas (2008) o corpo é fenomênico, isto é, um corpo que percebe e expressa em si mesmo diversos sentidos e significados. Assim, ele busca contrastar as ligações entre "corpo e experiência" e "corpo e cultura". Situando o ser humano como um sujeito corporificado, onde seus hábitos são construídos culturalmente. Assim, a ideia de corpo está ligada a todas as possibilidades que o cerca, "é a forma de o homem ser-no-mundo" (GONÇALVES, 1994, p.102), é a maneira que o corpo humano se enxerga numa unidade expressiva da existência (FREITAS, 1995); ou seja, este corpo pensa, sente e age. Para ser (no seu sentido verbal) humano precisa ser corporeidade, pois "o ser humano é corporeidade." (SANTIN, 1987, p.50).

A corporeidade é mutável e se transforma a cada novo aprendizado não se desvinculando dos anteriores. As experiências que passamos e vivenciamos, os hábitos e os costumes vão reverberar nesta corporeidade, ou seja, na sua maneira de agir no mundo (MERLEAU-PONTY, 2006a; FREITAS, 1995; GONÇALVES, 1994). Desta forma, através das contribuições trazidas, compreendemos que a corporeidade é inseparável do que é ser humano, ou seja, uma característica essencial e intrínseca 
das pessoas, contribuindo assim ao seu desenvolvimento que é sempre somado a cada nova experiência corporal que se é submetido(a), consequentemente se transforma e se adéqua a cada indivíduo de forma única e indissociável.

\section{CORPOREIDADE NA EDUCAÇÃO FÍSICA ESCOLAR}

A educação, por sua vez, direta e/ou indiretamente auxilia a instituir códigos morais, ora estabelecendo condutas, ora reprimindo as possibilidades de expressão do corpo, ocasionando um distanciamento das vivências do sujeito e sua aprendizagem. Ter a consciência que deve se trabalhar através da corporeidade na aprendizagem provoca uma compreensão geral na relação entre corpo, aprendizagem e cultura. Entendendo que o corpo não é um instrumento desassociado das práticas educativas, pois as produções humanas como ler, escrever, brincar, jogar, entre outras atividades, só são possíveis por sermos "corpo" (LÓPEZ-IBOR; ALIÑO, 1974).

Dentro do ambiente escolar, a Educação Física acabou por se tornar o componente curricular responsável por trabalhar com a prática corporal, e, por ter este perfil, por algumas vezes, se embasa na preparação de corpos disciplinados e submissos, procurando sempre extrair o melhor daquele corpo num ciclo de competição, pela busca pela vitória ou poder ou vitória. A escola assim se torna um ambiente que se promove o ato de instruir corpos em nome da saúde, da higiene e da moral (ARAÚJO, 2002), tendo na Educação Física um componente curricular propício para esta demanda.

[...], por exemplo, a fila, a carteira, o treino para a escrita, os exercícios com dificuldades crescentes, a repetição, a presença num tempo e num espaço recortados, a punição pelo menor desvio de conduta, a vigilância por parte de um mestre ou monitor, as provas, os exames, os testes de aprendizagem e de recuperação, o treinamento dentro de padrões e normas fixos. E mais, os resultados dos esforços pedagógicos sendo permanentemente avaliados por critérios também eles padronizados, leva a uma simples análise de boletins, que sirva para medir os casos que desviam, portanto, serve para marcar, excluir, normalizar (ARAÚJO, 2002, p. 79).

Outro importante autor que estudou sobre essa disciplinarização dos corpos, e cabe trazermos para o texto, foi Foucault (1987), ele sinalizou para a importância de dominar corpos e o fazer corporal para haver um controle social. Assim, compreendemos que algumas expressões da Educação Física escolar utilizaram-se, e ainda utilizam desses princípios durante as suas aulas com o intuito de promover cada vez mais um corpo disciplinado, um corpo compreendido como "bonzinho" e que apenas obedece e não contesta as instruções, sendo proibido de se expressar livremente. Assim, como área de atuação a Educação Física, por algumas vezes, se pautou pela preparação de corpos disciplinados e submissos, a serviço do poder, ou ainda, do rendimento. Mostrando como a forma de moldar o corpo e se relacionar com ele está intrinsecamente relacionado com o sistema econômico e político, produzindo indivíduos que produzam cada vez mais lucros e sejam doutrinados a não se revoltarem (BRUHNS; GUTIERREZ, 2000).

Em contrapartida Gonçalves (1994) argumenta que a Educação abraça o indivíduo como um todo e os valores e objetivos da Educação Física estendem-se tanto no âmbito pessoal quanto social sendo em sua totalidade Educação. Logo, a Educação Física deve ter consciência do seu papel dentro do ambiente escolar trabalhando de forma consciente e responsável com seus alunos e alunas, em busca de uma consciência corporal (GONÇALVES, 1994), como também autonomia no expressar-se através do corpo, considerando sua corporeidade e toda a história trazida consigo. 
Por ser educação e fazer parte da história, a Educação Física escolar passou por distintos momentos históricos que refletiam o momento social em questão. Algumas dessas tendências pedagógicas tinham como foco a reprodução e o ensino de gestos motores, outras traziam uma gama de conhecimento mais variado. Alguns exemplos dessas tendências são: Humanista; Fenomenológica; Psicomotricidade, baseada nos Jogos Cooperativos; Cultural; Desenvolvimentista; InteracionistaConstrutivista; Crítico-Superadora; Sistêmica; Crítico-Emancipatória; Saúde Renovada (DARIDO, 2005), compreendemos que as tendências pedagógicas não possuem uma ordem cronológica exata e precisa em todo o território brasileiro, por isso as citamos de forma livre, sem nenhum tipo de ordenamento. Assim, dentre várias opções, porém considerando nosso entendimento de Educação Física escolar, optamos neste trabalho nos embasar na tendência pedagógica Construtivista Interacionista, pois enxergamos a mesma como uma das tendências pedagógicas da Educação Física que retrata a corporeidade como acreditamos.

Educação Física também é postural, o que poderia ser desenvolvido em sala de aula. Educação Física é prazer, é socialização, que pode ser desenvolvida com atividades em sala, em pé, sentado, andando, marcando ritmo. Alfabetização é raciocínio matemático, é afetividade, é motricidade, que podem ser aprendidos também pulando corda ou brincando de amarelinha (FREIRE, 1997, p. 197).

A base desta tendência pedagógica tem o movimento como forma de ensino, independente do local onde o ensino aconteça (nas quadras, nas salas de aulas, nas praças, etc.), sendo o principal para o(a) professor(a) trabalhar de forma integral com seus alunos e suas alunas. Tendo o corpo com seus significados e sentidos (a corporeidade) como principal ferramenta para auxiliar esta vivência e ensinamento para os(as) educandos(as) (FREIRE, 1997). Gonçalves (1994) também ressalta que a construção do ser humano tanto na esfera pessoal quanto social está envolto à Educação Física e estende sua totalidade aos valores-fins da Educação numa relação singular. Complementando que a função pedagógica da Educação Física auxilia no desenvolvimento do indivíduo; enfatizando ainda o processo de formação da personalidade dos alunos e alunas como meio de desenvolver e colocar em ordem sua vida pessoal (GONÇALVES, 1994).

Dessa forma, a Educação Física deve aproveitar a sua particularidade dentro da escola (componente curricular que trabalha explicitamente com o corpo) para estimular a compreensão e vivência da corporeidade com seus(suas) alunos(as). Assim, a Educação Física é o caminho em que se instrui a perceber e "sentir-se corporeidade" constitui-se num alicerce ao modo de ser do homem que se distancia dos animais por se fazer presente na corporeidade, que reverbera em todas as práticas humanas (SANTIN, 1987). Enxergando em sua essência a importância de trazer autonomia corporal e o reconhecimento histórico para as atividades da cultura de movimento, estimulando a percepção das(os) estudantes que seus corpos são integrantes ativos no mundo, sendo um conhecimento "[...] que vai sendo construído e reconstruído ao longo de nossas vidas e da história." (MENDES; NÓBREGA, 2009, p. 6)

\section{OS RESULTADOS E DISCUSSÃO}

\subsection{A corporeidade para as professoras}

Para começarmos a entender a visão que os(as) estudantes têm sobre corporeidade, achamos necessário compreendermos como as professoras pesquisadas a conceituam. Neste tópico 
analisaremos as respostas sobre essa temática, para definirmos como as mesmas interpretam o sentido de corporeidade.

Ambas as professoras pesquisadas assinalaram em suas respostas que, "sim", é importante trabalhar com a corporeidade durante as aulas, percebendo assim que esta temática ocupa um papel essencial para a práxis da Educação Física se tornando uma referência ao tentar compreender tanto o seu próprio corpo, quanto o corpo do próximo, o que é salientado por Morais (2013) por temos o nosso corpo como primeiro fundamento, numa busca por uma consciência corporal que é construída a partir das vivências de maneira única não impondo nenhum tipo de padrão a ela. Umas das justificativas para essa importância, de acordo com a Professora Z, é que: "a mente e o corpo não estão dissociados", ou seja, estão interligados no processo de ensino e aprendizagem das aulas de Educação Física e é importante que não haja essa separação para conseguir enxergar o aluno e a aluna de forma integral.

Questionadas se abordam a corporeidade em suas aulas as duas professoras responderam que sim. Pedimos para elas justificarem, caso a resposta fosse positiva, e as justificativas foram: a corporeidade está presente "nas aulas práticas e teóricas" (PROFESSORA Z) de Educação Física; "com base dos alunos possuírem pouca experiência corporal e motora, trabalho em todos os conteúdos" (PROFESSORA X). Desta forma, interpretamos que há uma preocupação em identificar, nos(as) estudantes, o nível de percepção corporal deles(as), para assim elaborar uma estratégia de trabalho que faça uma junção tanto das necessidades percebidas quanto nos conteúdos propostos. Ou seja, indo a encontro com o que a Base Nacional Comum Curricular (BNCC) de Educação Física traz que é proporcionar aos alunos e as alunas o máximo de experiências corporais, buscando desenvolver e ampliar o conhecimento das diferentes práticas que possam estar associadas ao corpo (BRASIL, 2018).

Como vimos anteriormente, na reposta da Professora $Z$, ela relaciona corpo e mente de forma indissociável, associando-os principalmente a construção de conhecimento, evidenciando a importância da compreensão e aplicação da corporeidade dentro do contexto escolar. Assim corroborando com o pensamento de Moraes (1997), que diz ser importante conhecer o processo em que ocorrem as relações em suas diversas manifestações desde as físicas, biológicas, psicológicas sem esquecer as sociais, culturais e educacionais, levando em conta sempre a individualidade de cada sujeito resultante de um diálogo criativo entre "mente" e "corpo", onde há reciprocidade entre eles, corpo e mente, acontece de forma orgânica e automática, de modo consciente ou inconsciente resultando numa integralidade na maneira com que o indivíduo se situa no tempo e no espaço. 0 corpo e sua forma se tornam símbolos e uma marca do que ele já foi exposto em sua história, de acordo com Reich (1995; 1998), numa espécie de couraça muscular, que em sua grande maioria atua como forma de proteção para transitar nas diversas circunstâncias que a vida proporciona.

Lowen (1989) ressalta a importância do "estar vivo", não apenas no sentido fisiológico, mas no sentido de estar e se fazer presente no mundo, sem imposições de padrões, de forma livre incorporar e expressar no mundo, se manifestando corporalmente. Assim, a importância da corporeidade nas aulas de Educação Física é justificada pela Professora X como um momento que: "conseguimos enfatizar o aprendizado através da interação corporal, troca de experiências e a própria vivência corporal". Desse modo, podemos apostar que as atividades durante as aulas proporcionam aos(as) alunos(as) uma quantidade maior de novas possibilidades e de interação consigo e com o outro. 
Percebemos então, através dos questionamentos feitos às professoras e de suas respostas, que a corporeidade é algo presente durante suas aulas de Educação Física, e ainda assim notamos o quanto percebê-la nesses momentos de interação corpo e mente acrescenta positivamente ao conhecimento amplo dos(as) estudantes. Não somente percebê-la, mas entender que para que ocorra tal interação, como citado anteriormente, um desenvolvimento integral, deve-se levar em conta a individualidade e a necessidade de cada um(a), cabe assim ao(a) docente identificar e promover estratégias que possam suprir essas necessidades, levando em conta as peculiaridades de cada um, porém buscando ainda uma interação entre estudante, proporcionando uma troca de vivências, expandindo ainda mais - leque de possibilidades desses(as) alunos(as) dali pra frente, uma preocupação que as entrevistadas dizem ter no processo pedagógico. Importante ressaltar que esta carga de trabalho de identificação das(os) docentes em relação as(aos) alunas(os) deve ter um suporte do sistema educacional como um todo, pois não podemos (e nem devemos) dissociar a vontade de trabalhar de maneira integral com cada estudante e a realidade de materiais ou tempos ou quantitativo que o sistema educacional pode vir a impor.

Como último ponto do questionário das professoras, foi pedido para que elas definissem corporeidade, suas respostas foram as seguintes: "A forma com que o corpo se relaciona com o mundo" (PROFESSORA Z); "É a tentativa do ser humano se entender com o mundo através dos sentimentos construídos para conviver com a sociedade. $E$ isso só é possível a partir do autoconhecimento e das experiências vividas" (PROFESSORA X). Notamos em suas respostas uma simetria no momento em que elas evidenciaram a importância da relação que o corpo tem com o meio que vive num processo de socialização e como os conhecimentos que são adquiridos vêm a partir das experiências vividas ao longo do tempo. Ainda assim, percebemos o quanto as professoras pesquisadas fazem uma ligação e, na maioria das vezes, trazem o corpo como conceito e definição únicos de corporeidade, limitando seu entendimento a algo que os limites deveriam ser ultrapassados num processo de compreensão racional e lógica.

Merleau-Ponty (2006b) evidencia que a consciência e a mente são resultado do equilíbrio entre a corporeidade, o prazer e o jogo, permitindo ao ser humano através da corporeidade ser e estar no mundo. Hugo Assman (1996, p. 90) diz ainda que como "organismo vivo somos também um sistema perceptivo e cognitivo", ou seja, o desenvolvimento da imagem que temos do real se dá a partir do que recebemos dia após dia, tudo está ligado à corporeidade e é indissociável. Em suas respostas as Professoras X e Z ressaltam a corporeidade como a interação do ser humano com o mundo e são nessas noções do mundo percebido, que as realidades estruturais se manifestam na corporeidade. $E$ é por meio do corpo que o indivíduo de forma sensível se fixa no mundo, é em sua experiência corporal, que "redescobre a unidade fundamental do mundo como mundo sensível." (CHAUI, 1980, p. 11). Evidenciando que de maneira sutil nos estabilizamos no mundo assimilando os sentidos existência e vivência corpórea numa constante troca. Assim, "o corpo é a forma escondida do ser próprio ou, reciprocamente, que a existência pessoal é a retomada e manifestação de um ser em situação." (MERLEAU-PONTY, 2006a. p. 229).

\subsection{A corporeidade para os alunos e alunas}

Com o propósito de entender a corporeidade através dos(as) discentes, perguntamos a eles(as) se costumavam participar das aulas de Educação Física, todos(as) os(as) alunos(as) pesquisados(as) assinalaram que "sim", que participam das aulas, evidenciando assim uma boa adesão às aulas de Educação Física na Escola Vital. 
Em contrapartida, foi perguntado aos(as) mesmos(as), através do questionário, qual ou quais eram os conteúdos que a professora de Educação Física ministrava durante suas aulas, e como conteúdo mais recorrente, apontaram os esportes. Dentre eles, os(as) estudantes citaram futebol, voleibol e, 8 (oito) dos(as) 13 (treze) alunos(as) pesquisados(as), apontaram a ginástica artística. Ainda nesse questionamento, sobre quais conteúdos estão presentes nas aulas de Educação Física, foi evidenciado por 2 (dois) alunos a presença de conteúdos teóricos, com a professora trabalhando: "Ginástica, conceitos sobre esportes, etc." (ALUNO I); "Prática e teórica" (ALUNO IV). Percebemos por meio dessas respostas, juntamente com a observação informal do dia da coleta dos dados, pois se tratava de uma aula teórica em sala de aula, que em sua metodologia as professoras utilizam de momentos e ambientes separados para dividir o conhecimento teórico, ou seja, elas fragmentam suas aulas entre o espaço da quadra, destinado aos conteúdos práticos e a sala de aula para conteúdos teóricos. Este fato não é uma regra, pois o conhecimento pode ser passado em qualquer ambiente em que $\mathrm{a}(\mathrm{o})$ docente e $\mathrm{a}(0)$ aluna(o) estejam e não necessariamente deve ser restrito a um espaço físico, entretanto isso depende muito da metodologia adotada pelo(a) professor(a) em suas aulas.

Uma aula estritamente teórica num ambiente de sala de aula com um assunto, muitas vezes, engessado, monótono pode não vir a despertar interesse por parte dos(as) estudantes. Já uma aula que englobe o conhecimento como um todo, onde teoria e prática são vistos de forma indissociável, são mais atrativos, até para o entendimento do corpo discente que a fragmentação pode distanciar de um conhecimento efetivo. Assim, concordamos com a visão de Freire (1997) em que o conhecimento pode e deve ser transmitido através de práticas que envolvam o aluno como todo, possibilitando um aprendizado de forma integral. Em qualquer espaço que a escola disponha para as aulas de Educação Física, o conhecimento será transmitido, porém não é somente nas aulas ditas teóricas que os saberes podem ser passados de forma conceitual. Consoante ao pensamento de Ghilardi (1998) evidenciamos que numa aula prática a compreensão e assimilação dos(as) alunos(as) ao que os(as) professores(as) se dispõem a ensinar é muito mais proveitoso, pois são nos momentos de interação que o conhecimento é posto à prova e onde a corporeidade pode vir a se construir de forma consciente e autônoma, unindo-se a teoria e a prática. No meio escolar há uma reflexão acerca da relação entre teoria e prática durante as aulas de Educação Física e de acordo com Borges (1997) $\mathrm{a}$ (o) docente deve possibilitar ao estudante essa associação entre a teoria e a prática, pois elas são indissociáveis e contribuem para a construção consciente não somente do corpo, mas do ambiente ao seu redor. Assim, compreendemos que, independente do ambiente em que a aula se dá, o conhecimento deve ser passado aos alunos sem que haja essa limitação do espaço, possibilitando experiências que acrescentem ao seu desenvolvimento.

Desta forma, corroboramos que a corporeidade é, na maioria das vezes, compreendida numa separação entre corpo e mente (SANTIN, 2013), entretanto, esse conhecimento deve se construir de maneira total, assim como as aulas teóricas e as aulas práticas não devem ser compreendidas separadamente e sim com a visão que uma completa a outra e pertence a outra. Ou seja, fazemos uma relação direta entre a separação de aulas teóricas e práticas com a visão fragmentada do indivíduo entre corpo e mente. Pois, se ainda há uma compreensão de que as aulas teóricas só podem ser aplicadas dentro da sala de aula (com o corpo contido, "engessado" atrás da mesa) e as aulas práticas apenas podem ser dadas nas quadras ou nos pátios (com o corpo "livre" pra se movimentar), fica nítido que por mais que as professoras digam que não separam corpo da mente, acabam por demonstrar que ainda há essa visão e/ou uma aceitação desta separação. 
Além disso, ainda através das respostas dos(as) discentes sobre os conteúdos aprendidos nas aulas de Educação Física, percebemos o quanto as expressões "exercício físico" (ALUNO VII); "atividade física aeróbia e anaeróbia" (ALUNO IX), aparecem nas respostas, nos levando a pensar sobre o educar para a saúde e o quanto o corpo e sua "boa forma" são relevantes para esses(as) estudantes. Martins (2015, p. 175) aponta que se deve "aprender a cuidar da saúde e do corpo" e que é de responsabilidade do ser humano cuidar de si mesmo, promovendo seu bem-estar. Trata-se de uma aprendizagem formal, pois assim como agimos, pensamos e sentimos participando na experiência vivida. Como vimos nas respostas dos Alunos VII e IX notamos uma preocupação em evidenciar e se ter um corpo saudável como objetivo e resultado durante as aulas de Educação Física. Entretanto atentamos para o perigo ao não analisar de forma simplista o bem estar do indivíduo, ou seja, seu corpo de maneira "saudável" sem levar em consideração a sua corporeidade, consequentemente, sua individualidade como sujeito, considerando somente o seu corpo de maneira fisiológica, muitas vezes com o propósito de gerar resultados.

Para buscar observar se esses(as) alunos(as) compreendiam a corporeidade como forma de se expressar no mundo, foi perguntado se as aulas de Educação Física os(as) ajudam a se manifestar corporalmente, todos(as) assinalaram que sim e quando indagados a responder o "por quê" obtivemos as mais diversas repostas. Dentre elas, uma chama atenção, porque de acordo com pesquisado o momento das aulas de Educação Física "é o único dia em que pratico alguma atividade física" (ALUNO I), corroborando ao entendimento de que é durante as aulas de Educação Física o principal, se não o único, momento em que os(as) alunos(as) podem se exercitar, se mover, lembrar que tem um corpo dentro do ambiente escolar. Freire (2013) já nos alertava que habitualmente os(as) alunos(as) tem suas mentes matriculadas nas escolas, não seus corpos, e essa observação parece que continua sendo verossímil.

As aulas de Educação Física são vistas como um momento onde os(as) discentes têm liberdade em se manifestar corporalmente. Já a percepção dessa expressão, para os alunos II, III, IV, V e VI está inteiramente ligada ao desenvolvimento do movimento dos seus corpos e que ainda os ajudaria numa "melhor visão das práticas", sendo o corpo visto num âmbito de conhecimento que tem como única condição o movimento. Para a maioria dos(as) estudantes pesquisados(as), se expressar corporalmente está relacionado a ter uma "boa forma". Podemos relacionar esta visão, do corpo voltado para aptidão física, com uma visão cada vez mais dividida e sistematizada, se transformando num "corpo da mídia", "corpo-estético", "corpo-manequim", "corpo-instrumento", etc., ou seja, num corpo que se torna algo para se alcançar, numa espécie de objetivo (VINCENT citado por MARTINS, 2015). Percebemos através deste estudo que os(as) alunos(as) deixam transparecer uma preocupação em se ter o corpo saudável e serem fisicamente aptos(as), características essas que são advindas principalmente das mídias atuais que as colocam relacionadas a um corpo ideal, como um objetivo a ser alcançado. Assim, entendemos a importância de abordar o assunto corpo durante as práticas pedagógicas, num processo de cruzamento de conhecimentos a fim de auxiliar 0 entendimento das peculiaridades presentes ao ser humano e intrínseco ao corpo de maneira geral, pois, desta forma, é por meio do corpo, que a nossa individualidade é compreendida. (ASSMANN, 1994).

Desta forma, consoante ao pensamento de Soares (2002), entendemos que os conteúdos presentes nas aulas de Educação Física, devem ser abrangentes aos mais diversos assuntos e experiências vividas através das práticas corporais, da corporeidade em ação, assim propiciando aos(as) aluno(as) irem muito além de experiências ligadas a uma prática, que tenha fins de rendimento e estética 
corporal, ou ainda, ser uma aula onde se impõe a maneira de como o corpo deve ser moldado, sem respeitar a individualidade da história daquela pessoa e daquele movimento que passa a ser compreendido, realizadO e modificado por quem o pratica, se transformando constantemente, o que pode e deve auxiliar numa visão crítica do mundo, onde as diferenças (sejam elas regionais, entre bairros e/ou diversos locais) são observadas e respeitadas pois são vistas dentro de uma contextualização histórica de quem cria e recria esta ação (MENDES; NÓBREGA, 2009)

Pois essa prática corporal não deve ser vista como reprodução fora de sua contextualização, pois "não trabalhamos com máquinas a serem melhoradas em seu rendimento, mas sim, com a corporeidade viva, existencial, racional e sensível" (MOREIRA et al, 2010, p.119). Assim, a abordagem da corporeidade nas aulas de Educação Física não deve estar ligada aos padrões estéticos ou pela busca por rendimentos, essa abordagem durante as aulas é importante justamente por visar entender cada aluno(a) de forma individual e única, pois como citado acima, não somos máquinas que trabalham de forma programada e metódica e que vão se desenvolver de forma esperada e da mesma maneira. A corporeidade vem dar contraponto a essa ideia. Por isso a sua importância durante as aulas de Educação Física, pois cada um de nós somos seres únicos e nos moldamos a partir daquilo que vivenciamos, longe de padrões de beleza num processo de desenvolvimento de ser e se identificar no mundo. Esse processo é importante, pois leva aos(as) alunos(as) à compreensão de como o seu corpo pode reagir e interagir de forma completamente distinta do seu colega mesmo que expostos à mesma atividade e vivência, e isso é algo normal, pois somos diferentes, sem precisarmos ser desiguais.

Por fim, foi perguntado aos(as) estudantes o que eles(as) entendiam por corporeidade. Já no momento da coleta de dados, percebeu-se um estranhamento quanto à palavra corporeidade assim que se deparavam com a pergunta. Os Alunos IX, V, I e VIII definiram corporeidade, bem como a maioria, como algo relacionado ao corpo, entretanto, para alguns(mas) deles(as) a corporeidade está relacionada à idade, para o Aluno $\mathrm{V}$ "como o corpo se comporta durante determinada idade". Essa definição não está totalmente equivocada, pois é algo que vai se adquirindo com o passar do tempo, a partir de suas vivências, porém, essa definição para eles está mais relacionada à separação silábica da palavra e o que ela os remetia naquele momento. Em sua resposta o Aluno VII disse que "apesar de não ter ouvido essa palavra, pra mim essa palavra tem o sentido de corpo em movimento", assim como o Aluno IV que entende por corporeidade a "movimentação do corpo".

Percebemos que apesar de não compreenderem totalmente o termo corporeidade, assim como as professoras pesquisadas, os(as) alunos(as) relacionam e conceituam a mesma com o corpo e o ato de se movimentar. Salientamos ainda através de Nancy citado por Martins (2015) que a corporeidade não se trata somente disso, além do movimento ela representa a existência do corpo, ela une e se intera do espaço, consequentemente situa o ser humano no mundo com o corpo de maneira objetiva e subjetiva. Sendo assim, é importante ter um cuidado ao abordar esse tema e deixar evidente que uma atividade pode e será vivenciada de maneira diferente pelos indivíduos mesmo que eles(as) tenham características parecidas, pois o contexto ao qual ele(a) está inserido influencia, assim como reflete na sua maneira de agir, personalidade, escolhas, dentre outros. Logo, essa individualidade deve ser percebida pelos alunos para que não se condicionem a uma mesma maneira de agir, pensar, etc., como dito anteriormente. A partir disso entendemos ainda que o passar do tempo não é necessariamente uma garantia para que haja a percepção do conceito e da importância da corporeidade durante as aulas de Educação Física, mas sim, a vivência, a experimentação e a individualidade de cada aluno a partir das suas percepções serão capazes disso. 


\section{CONSIDERAÇÕES FINAIS}

Mediante a percepção da amplitude da corporeidade, sua relevância bem como a importância por estar presente nas aulas de Educação Física, é fundamental que esta seja compreendida com clareza no contexto educacional. Nessa perspectiva investigativa, a pesquisa se realizou numa reflexão a respeito do que é corporeidade, sua importância e se está presente nas aulas de Educação Física, na perspectiva dos(as) estudantes e das professoras. Revelando um cenário carente de completude acerca dessa compreensão e como a corporeidade está inserida efetivamente durante essas aulas de Educação Física na Escola Vital.

Assim, a partir de uma pesquisa descritiva com abordagem qualitativa buscando compreender cada indivíduo pesquisado, observou-se que para as professoras pesquisadas a corporeidade é importante e deve estar presente nas aulas de Educação Física, uma vez que elas concordam que os(as) discentes devem compreender o corpo em sua totalidade, que não deve haver uma dissociação entre corpo e mente, apesar de trabalharem de forma fragmentada com os conteúdos ditos teóricos e práticos.

Quanto à percepção dos(as) alunos(as) ao que a pesquisa objetivava, bem como a relevância do tema pesquisado para eles(as), foi possível observar a falta de familiaridade até mesmo com a palavra corporeidade. Entretanto, a partir da análise de suas respostas percebemos que o conceito de corporeidade lhes remetia unicamente ao corpo e sua forma física, sem deixar evidente a sua percepção em como a corporeidade poderia estar inserida durante as aulas de Educação Física.

Através destes achados nesta pesquisa, consideramos que docentes de Educação Física podem e devem deixar mais claro sobre a importância da corporeidade para auxiliar a compreensão dos(as) alunos(as) que eles(as) pertencem efetivamente ao mundo, que eles(as) fazem parte e interagem ativamente com este mundo, pois consideramos que se falta essa consciência a eles(as), falta o entendimento de pertencimento, de autonomia, de coletividade e de sociedade.

Com isso, essa pesquisa cumpriu com o objetivo proposto em se afirmar a necessidade e a importância da presença da corporeidade nas aulas de Educação Física, durante o período escolar, e que se efetive num trabalho amplo, abrangente para que os ensinamentos a respeito do corpo e a assimilação da corporeidade aconteçam de maneira ampla no dia a dia dos(as) alunos(as), para repercutir numa leitura mais crítica de mundo ao reconhecer como a prática corporal é atribuída de formas distintas em diferentes localidades, pois há sentidos, ânimos e significados particulares. Mais do que se preocupar em ensinar um movimento específico, o(a) docente deve se preocupar em contar e respeitar a história desse movimento e estar atento(a) as alterações estão inerentes a prática viva deste movimento.

\section{REFERÊNCIAS}

ARAÚJO, I. L. Da "pedagogização" à educação: acerca de algumas contribuições de Foucault e Habermas para a filosofia da educação. Revista Diálogo Educacional, Curitiba, v. 3, n. 7, p. 7588, set./dez. 2002.2 Disponível em: <https://periodicos.pucpr.br/index.php/dialogoeducacional/article/view/4885> Acesso em: 23 jun 2020.

ASSMANN, H. Paradigmas educacionais e corporeidade. 2. ed. Piracicaba, SP: UNIMEP, 1994.

BARDIN, L. Análise de conteúdos. São Paulo: Augusto Pinheiro, 2016. 
BORGES, C. M.F. Professor de Educação Física e a Construção do Saber. Campinas: Papirus, 1997.

BRASIL. Base Nacional Comum Curricular (BNCC). Educação é a Base. Brasília, MEC/CONSED/UNDIME, 2018. Disponível em: <http://basenacionalcomum.mec.gov.br/images/BNCC EI EF 110518 versaofinal site.pdf>. Acesso em: 25 jun. 2020

BRUHNS, H. T e GUTIERREZ, G. L. (orgs.) 0 corpo e o lúdico: ciclo de debates lazer e motricidade. Campinas: Autores Associados, 2000.

CHAUI, M. In: Merleau-Ponty, textos escolhidos. Organização, tradução e comentários, Marilena Chaúi. São Paulo: abril cultural, 1980.

DARIDO, S. C. Os conteúdos da Educação Física na escola. Educação Física na escola: implicações para a prática pedagógica. Rio de Janeiro: Guanabara Koogan, 2005.

FREIRE, J. B. Educação de corpo inteiro: Teoria e Prática da Educação Física. São Paulo: Scipione, 1997.

. Métodos de confinamento e engorda (como fazer render mais porcos, galinhas, crianças...) In.: MOREIRA, Wagner Wey (org). Educação física \& esportes: perspectivas para o século XXI. 14 ed. Campinas: Papirus, 2013

FREITAS, G. G. de. O esquema corporal, a imagem corporal, a consciência corporal e a corporeidade. Tese (mestrado) - Área de Concentração: Educação Motora, Universidade Estadual de Campinas. Campinas-SP, p.49. 1995.

FOUCAULT, M.Os corpos dóceis. In: Vigiar e Punir: nascimento da prisão. Tradução de Raquel Ramalhete. Petrópolis, Vozes, 1987.

GIL, A. C. Métodos e técnicas de pesquisa social. São Paulo: Atlas, 2008.

GHILARDI, R. Formação profissional em educação física: a relação teoria e prática. Motriz. v. 4, n. 1, Junho, 1998. Disponível em: <https://www.rc.unesp.br/ib/efisica/motriz/04n1/4n1 ART01.pdf> Acesso em: 22 jun 2020.

GONÇALVES, M. A. S. Sentir, pensar e agir: corporeidade e educação. 9. ed. Campinas, SP: Papirus, 1994.

INFORSATO, C. F.; FIORANTE, F. B. Corporeidade: por uma abordagem humanizadora do corpo em busca da existencialidade. Revista Mackenzie de Educação Física e Esporte. São Paulo. v. 9. n. 2. 2010. Disponível em: <http://editorarevistas.mackenzie.br/index.php/remef/article/view/3486> Acesso em: 23 jun 2020.

JOÃO, R.B.; BRITO, M. Pensando a corporeidade na prática pedagógica em educação física à luz do pensamento complexo. Revista Brasileira de Educação Física e Esporte, São Paulo, v.18, n.3, p.263-72, jul./set., 2004.

LÓPEZ-IBOR, J. J.; ALIÑO, J. J. L. F. El cuerpo y lacorporeidad. Madrid: Gredos, 1974.

LOWEN, A.Medo da vida. Tradução Maria Sílvia Mourão Netto. São Paulo: Summus, 1989. 
MARTINS, E. C. A corporeidade na aprendizagem escolar (Entrelaços fenomenológicos do pensar e agir). Educar em Revista, Curitiba, Brasil, n. 56, p. 163-180, abr./jun. 2015. Disponível em: <https://www.scielo.br/pdf/er/n56/0101-4358-er-56-00163.pdf> Acesso em. 22 Jun 2020

MENDES, M. I. B. DE S.; NÓBREGA, T. P. DA. CULTURA DE MOVIMENTO: REFLEXÕES A PARTIR DA RELAÇÃO entre CORPO, NATUREZA e CULTURA. Pensar a Prática, v. 12, n. 2, 26 ago. 2009. Disponível em: < https://www.revistas.ufg.br/fef/article/view/6135/5361> Acesso em 11 ago 2020.

MERLEAU-PONTY, M. Fenomenologia da percepção. Traduzido por Carlos Alberto Ribeiro de Moura. 3. ed. São Paulo: Martins Fontes, 2006a.

A estrutura do comportamento. São Paulo: Martins Fontes, 2006b.

MORAIS, J. F. R. de. Consiencia corporal e dimensionamento do futuro. In: MOREIRA, W. W. (Org.). Educação fisica \& esportes: perspectivas para o seculo XXI. Campinas: Papirus, 2013.

MOREIRA, W. W. Corporeidade e a busca de novas palavras para o saber: uma das tarefas da Educação Motora; Anais do I Congresso Latino Americano de Educação Motora. II Congresso Brasileiro de Educação Motora - Foz do Iguaçu, 1998.

MORAES, M. C.O paradigma educacional emergente. Campinas: Papirus, 1997.

MOREIRA, W. W.; Virtuoso Júnior, J. S.; Barbosa Neto, O. y Simões, R. M. R. (Orgs.). Educação física, esporte, saúde e educação. Uberaba/MG: Universidade Federal do Triângulo Mineiro, 2010.

MOREIRA, W, W. (Org.). Fenômeno esportivo no início de um novo milênio. Piracicaba: Unimep, 2000.

REICH, W.A função do orgasmo. Problemas econômico-sexuais da energia biológica. Tradução de Maria da Glória Novak. 19 ed. São Paulo: Brasiliense, 1995.

REICH, E.Energia vital pela Bioenergética suave. Tradução de Claudia Abeling. São Paulo: Summus, 1998.

SANTIN, S. Educação Física: uma abordagem filosófica da corporeidade. Ijuí, RS: Livraria UNIJUÍ Editora, 1987. 125p.

. Perspectivas na visão da corporeidade. In MOREIRA, W. W. (Org). Educação física \& esportes: Perspectivas para o século XXI. Campinas: Papirus, 2013.

SOARES, C. L. Imagens da educação no corpo: estudo a partir da ginástica francesa no século XIX. $2^{\mathrm{a}}$ ed. Campinas: Autores Associados, 2002. 